\title{
Nucleation and Crystallization of Low Isotatic Polypropylenes with Statistically Distributed Stereoerrors
}

\author{
By Sabine HILD, ${ }^{1,2}$ Andreas BOGER, ${ }^{2,3, *}$ Carsten TROLL, ${ }^{4}$ and Bernhard RIEGER ${ }^{4}$
}

The time dependent crystallization of a low isotactic polypropylene with statistically incorporated stereoerrors was investigated by the combination of differential scanning calorimetry (DSC), wideangle X-ray scattering (WAXS) and scanning force microscopy (SFM). Owing to Scanning force microscopy (SFM) and WAXS experiments the crystallization of the sample in mixed $\alpha / \gamma$-form aggregates can be proposed. The nucleation and growth processes of crystallization in thin polypropylene films in real time were visualized with nanometer resolution by using SFM at variable temperature. During the isothermal crystallization from the melt initially crystals of the $\alpha$-form were developed. These lamellae act as nuclei for the further crystallization of $\gamma$ - and mixed $\alpha / \gamma$-lamellae, which can be observed at longer crystallization times. Time dependent SFM and WAXS experiments showed that due to the low amount of crystallizable, regular sequences and its statistical distribution only slow crystallization rates can be observed. These results form the basis for a better understanding of the crystallization of low crystallinity polypropylenes. The investigations clearly show that the distribution of the regular isotactic segments influences the crystallization properties of propene based TEP's. This opens the possibility to tailor not only the mechanical but also the thermal properties of elastomeric polypropylenes by changing the polymer microstructure. KEY WORDS: Elastomeric Polypropylene / Crystallization / SFM / WAXS /

The development of metallocene catalytic systems for the isospecific polymerization of olefins leads to new isotactic polypropylenes (i-PP) showing a wide variety of mechanical properties ranging form stiff thermoplastic to soft elastomeric ones. ${ }^{1}$ Within these polypropylenes, the low isotactic ones have attracted considerable interest because of their unique combination of facile synthesis, chemical inertness, and elastic properties. $^{2-8}$ The chain structure of these polypropylenes is explained in terms of chains consisting of alternating domains of more regular isotactic sequences, which are able to crystallize, and stereo-irregular, noncrystallizable sequences. 9,10 Due to the low amount of regular sequences, the polymers are characterized by a low degree of crystallinity. ${ }^{11-16}$ The crystalline domains are proposed to form a three-dimensional, physically crosslinked network ${ }^{17}$ for the flexible, irregular blocks providing an amorphous matrix. ${ }^{11}$ Due to the formation of this network, the polypropylenes behave like chemically crosslinked rubbers. ${ }^{11,18,19}$ In contrast to chemically crosslink rubbers the cross-links can easily be opened at increasing temperature. Therefore transitions between the elastomeric and the melt state can be initiated by temperature variation. Since these polymers posses the physical properties similar to chemical cross-linked rubber and the processing characteristics of thermoplastics they are called thermoplastic-elastic polypropylenes (TPE-PP). ${ }^{11,20}$

The mechanical properties of thermoplastic elastomers are strongly related to the size and distribution of the hard phase. ${ }^{21-25}$ In case of elastic polypropylene the mechanical properties are expected to depend on the size and distribution of the crystalline regions within the amorphous matrix. For high isotactic polypropylenes it has been shown that the random incorporation of defects of stereoregularity and regioregularity (stereoerrors) will reduce length of the regular isotactic crystallizable sequences and, therefore, reducing the crystallization rate and the degree of crystallization. ${ }^{26-28}$ Futhermore, it has been shown that in case of isotactic polypropylenes the formation of crystalline domains is correlated to the length of the isotactic blocks..$^{27,29-34}$ Using specific metallocene catalysts at varying polymerization conditions, such as monomer concentration temperature, nature of cocatalyst, ${ }^{1}$ low isotactic polypropylenes can be obtained containing different amounts and combinations of stereoerrors leading to high molecular weight atactic polypropylene, ${ }^{29,35-37}$ polypropylenes with an intermediate isotactic-atactic microstructure, ${ }^{6,29,38-40}$ stereoblock isotactic-atactic polypropyl-

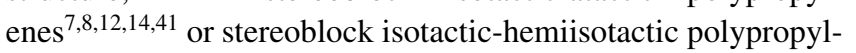
enes. ${ }^{42}$ Beside those, a new type of high molecular weight, low isotactic polypropylene has been synthesized by Rieger et $a{ }^{43-45}$ Due to the random incorporation of stereoerrors, these polypropylenes contain statistically distributed, isotactic sequences. ${ }^{31}$ Although the isotactic sequences are expected to be short, these polymers reveal a crystalline phase. Thus, the minimum block length of about 15 to 20 consecutive isotactic monomers $^{39,46}$ necessary for formation of crystalline domains is exceeded.

\footnotetext{
${ }^{1}$ Institute of Polymer Science, Johannes Kepler University of Linz, Altenberger Strasse 69, 4040 Linz, Austria

${ }^{2}$ Experimental Physics, University of Ulm, Albert-Einstein-Allee 11, 89081 Ulm, Germany

${ }^{3}$ Synthes $\mathrm{GmbH}$, Biomaterials, Eimattstrasse 3, 4436 Oberdorf, Switzerland

${ }^{4}$ Macromolecular Chemistry, Technical University Munich, Lichtenbergstrasse 4, 85747 Garching, Germany

*To whom correspondence should be addressed (Tel: +4161965 6409, Fax: +4161965 6604, E-mail: boger.andreas@ synthes.com).
} 
For isotactic-atactic stereoblock polypropylenes a degree of crystallinity below $5 \%$ has been reported. ${ }^{12-16}$ Even though, they were found to crystallize with a lamellar habit typical of much higher crystalline polypropylenes. ${ }^{29,47,48}$ Hence, it was of particular interest to analyze whether low isotactic polypropylenes with randomly distributed isotactic sequences are also able to form a crystalline morphology remiscent of the one found for higher isotactic one. To do so, the crystallization behavior and morphology of these new polymers have to be studied. Unfortunately traditionally applied techniques for in situ measurements of crystallization such as polarized optical microscopy (POM) are difficult to use. POM is practically impossible to use because the size of the crystallite are below the optical resolution limit. Likewise, due to the low amount of crystallinity, wide angle scattering WAXS and DSC will give only a limited amount of information. Therefore, new characterization techniques have to add to the compliant investigation techniques like WAXS.

The developments in the field of temperature dependent scanning force microscopy (SFM) overcome in part these experimental limitations. SFM provides new insight into the crystallization behavior, i.e., crystallization kinetics and morphology development in real time. Vancso and Miles have carried out pioneering work in this field. ${ }^{49,50}$ Following, a number of studies on different aspects of polymer crystallization have been published by various groups at room temperature $^{51-53}$ as well as on elevated temperature with active temperature control. ${ }^{54-60}$ The potential of the SFM approach at controlled temperatures in the study of the crystallization of low crystallinity polypropylenes was clearly demonstrated by Schönherr et al. ${ }^{61}$ For stereoblock low isotactic polypropylenes, they were able to show that in thin films the crystallization occurs in the form of lamellar crystals that developed from stable nuclei. Based on the observation of crosshatching they evidenced the formation of $\alpha$-phase isotactic polypropylene for low isotactic polypropylenes which have a stereoblock isotactic-atactic chain structure.

In this paper, we focus on the study of melting and crystallization of an elastomeric PP with statistically distributed stereo errors on different length scales. Since the crystallization conditions can influence the formation of the crystalline modification, samples prepared by different methods are investigated. Hot stage scanning force microscopy and $\mathrm{X}$-ray scattering methods were used to investigate the crystallization effects on the micrometer scale and compared with macroscopic properties, such as deformation behavior. To figure out if the change in chain microstructure leads to characteristic differences in the polymer properties compared to stereoblock polypropylenes, it was necessary to understand how and to what extent these low isotactic polypropylenes crystallize. Therefore, time and temperature crystallization experiments are performed using differential scanning calorimetry (DSC) or X-ray scattering techniques and SFM. The influence in the mechanical behavior was tested in stretching experiments.

\section{EXPERIMENTAL}

\section{Polymerization Experiment}

A low isotactic polypropylene has been prepared in toluene at $315 \mathrm{~K}$ using a $C_{1}$-symmetric ansa-zirconocene catalyst as described in. ${ }^{43}$ Methylaluminoxane and triisobutylaluminum were purchased from Witco (Greenwich, USA) and toluene for the polymerization reactions from Merck (Darmstadt, Germany). The ethylene-bridged zirconocene has been prepared as described in. ${ }^{43}$ The polymerization reactions were performed in a $0.5-\mathrm{L}$ Büchi steel reactor at constant pressure and temperature. The autoclave was charged with $200 \mathrm{~mL}$ toluene and with MAO cocatalyst and zirconocene dichloride. Subsequently, the polymerization temperature was adjusted to $315 \mathrm{~K}$ and the reactor was charged with propene up to a pressure of $600 \mathrm{kPa}$. The monomer consumption was measured using a calibrated gas flow meter (F-111C-HA-33P, Bronkhorst, Ruurlo, Netherlands) and the pressure was kept constant during the entire polymerization period (Pressure controller F-111C-HAP-602C-EA-33P, Bronkhorst, Ruurlo, Netherlands). Pressure, temperature and monomer consumption were monitored and recorded online to provide reversible processing conditions. The polymerization reaction was quenched with $\mathrm{MeOH}$, and the polymer products were precipitated pouring the toluene solution into an excess of $\mathrm{MeOH}$. The products were filtered off, washed with acidified methanol and dried in vacuum at $335 \mathrm{~K}$ overnight.

Molecular weight and molecular weight distributions were determined by gel permeation chromatography (Alliance GPC 2000, Waters, Millford, USA), $420 \mathrm{~K}$ in 1,2,4-trichlorobenzene) universal to polystyrene and relative to polypropene standards. For presented sample reveal a molecular weight of $160000 \mathrm{~g} / \mathrm{mol}$ with $M_{\mathrm{w}} / M_{\mathrm{n}}$ of about 1.8 .

NMR spectra have been used to calculate the concentration of isotactic pentads. For this purpose $15 \mathrm{mg}$ of the sample were dissolved in $500 \mu \mathrm{l}$ toluene in a $5 \mathrm{~mm}$ tube. ${ }^{13} \mathrm{C}$ NMR spectra were recorded on a Bruker AMX 500 spectrometer (Bruker $\mathrm{GmbH}$, Rheinstetten, Germany) operating at $353 \mathrm{~K}$. The analyzed sample contains $36 \%$ of isotactic pentads.

\section{Film Preparation}

Different types of films are used for the various analysis techniques. For DSC and WAXS investigations as well as for mechanical testing melt pressed films with a thickness of about $1 \mathrm{~mm}$ were used. SFM experiments are performed on $200 \mathrm{~nm}$ thick dip coated films. All films were stored for 6 month at room temperature under ambient conditions (30\% humidity, $278 \mathrm{~K}$ ) before further investigations to ensure that the samples are in thermal equilibrium.

\section{Melt Pressed Films}

To prepare melt pressed films $10 \mathrm{~g}$ granulated polymer were placed in between two glass plates covered with PTFE foils with a spacer of $1 \mathrm{~mm}$. The polymer was heated under constant low pressure $(2 \mathrm{kN})$ to $390 \mathrm{~K}$. When the temperature was 
reached and the sample was molten the pressure was increased up to $5 \mathrm{kN}$. After leaving the sample for $30 \mathrm{~min}$ at this pressure, the pressure was increasesd up to $20 \mathrm{kN}$. After another $30 \mathrm{~min}$ the sample was cooled down to room temperature with a cooling rate of $1.5 \mathrm{~K} / \mathrm{min}$. The thickness of the film was $1 \pm 0.01 \mathrm{~mm}$ determined using a micro-meter screw.

\section{DIP Coated Films}

For SFM experiments thin films on silicon substrates were prepared by dip coating. To prepare a dip coating solution, $100 \mathrm{mg}$ polymer was solved in $10 \mathrm{~mL}$ toluene. The solution was heated in a water bath at $350 \mathrm{~K}$ for $60 \mathrm{~min}$ to ensure the total dissolution of the polymer. A piece of freshly cleaned silicon was dipped into the hot solution for $10 \mathrm{~s}$. The sample was dried in vapor of the toluene for $30 \mathrm{~s}$. Films with thickness of about $200 \pm 50 \mathrm{~nm}$ were obtained.

\section{DSC Measurements}

Calorimetric investigations were carried out with a PerkinElmer DSC2 (Perkin Elmer, Wellesley, USA) differential scanning calorimeter using indium as a calibration standard. Small pieces of the melt pressed films were punched with a standard paper puncher. Disk-like samples of 5-10 mg were weighed and sealed into Perkin-Elmer aluminum DSC pans. The thermal treatment of the samples has been carried out in the DSC instrument under a nitrogen atmosphere. Heat flow data $\left(\mathrm{Jg}^{-1}\right)$ were taken during heating from $200-420 \mathrm{~K}$ with a rate of $10 \mathrm{~K} / \mathrm{min}$.

Melting transitions $T_{\mathrm{M}}$ (peak maximum of endothermic curve) and the heat of fusion $(\Delta H)$ were determined from the first DSC run. The accuracy of the estimated melting temperature is about $\pm 0.2 \mathrm{~K}$. The heat of fusion was determined with an uncertainty of $\pm 0.5 \mathrm{Jg}^{-1}$. For time dependent experiments small pieces of the melt pressed film were measured in given periods of time $(0.5 \mathrm{~h}-480 \mathrm{~h})$ after sample preparation. The different fractions of crystalline lamellae revealing melting transitions with maxima at $T_{\mathrm{M} 1}$ and $T_{\mathrm{M} 2}$ were determined from the corresponding heats of fusion, $\Delta H_{\mathrm{TM} 1}$, and $\Delta H_{\mathrm{TM} 2}$, respectively, were determined fitting Gaussian curves to the peaks.

\section{X-Ray Diffraction}

Crystallinity of the melt pressed sample was investigated using wide-angle X-ray scattering (WAXS). The WAXS investigations were performed at the polymer beamline A2 $(\lambda=1.5 \AA)$ at the HASYLAB at DESY in Hamburg and with a conventional Guinier-Lennier camera (Philips PW 1830/40, Philips Industrial \& Electro-Acoustic Systems Division, Almelo, Netherlands) using the $\mathrm{CuK}_{\alpha}$-line $(\lambda=1.51 \AA)$. Phosphor imaging-plates (IP) were used as detection unit for recording WAXS intensities. For these experiments at HASYLAB a new custom made experimental setup with a cylindrical curved IP was used. The radius of the cylinder corresponded to the distance between sample and IP. The advantage of this setup is the excellent resolution, which is comparable to a conventional GUINIER-camera, ${ }^{62}$ combined with the advantages of synchrotron radiation. The setup at HASYLAB was very suitable for investigations on the short time scale (low exposure times of $10 \mathrm{~s}$ ) for the first four hours. Single measurements to evaluate the crystallinity after certain days were carried out using the Guinier-camera also with IP as detector. The sample was punched out of the film in the same way as for the calorimetric measurements. Between the measurements the sample was kept at room temperature under ambient conditions (30\% humidity, $278 \mathrm{~K}$ ).

To investigate the recrystallization of the sample a small piece was placed in an oven, which is mounted in the beamline. At first the sample was melted $20 \mathrm{~K}$ above the melting temperature and cooled down with a constant rate of 1.5 $\mathrm{K} / \mathrm{min}$. The first WAXS diagram for the time measurement was recorded when room temperature was reached. Consecutively, to follow the first four hours of recrystallization WAXS are recorded in the beamline. WAXS diagrams taken after more than $24 \mathrm{~h}$ of crystallization were recorded using the Guinier-camera after certain days until 6 months.

To get information about the crystallinity $X_{\text {WAXS }}$ of the semicrystalline sample, the separation of crystalline and amorphous phase of the WAXS curves is necessary. As reference for the amorphous halo a WAXS record of a fully $\mathrm{X}$-ray amorphous polypropylene sample at room temperature was used. Comparing the amorphous halos of the semicrystalline sample and the amorphous sample taken at $493 \mathrm{~K}$ showed a high similarity of the WAXS records. Therefore we assumed the same X-ray scattering of the amorphous phase at room temperature for both samples, semicrystalline and the X-ray amorphous ones. Thus, the different amounts of scattering could be separated. The total crystallinity $\mathrm{X}_{\mathrm{WAXS}}$ was given by the ratio of the integrals obtained from the subtracted curve (WAXS record minus amorphous halo) and the whole curve corrected for the background. Presented curves were fitted using Lorentzian type curves, mainly for the characteristic reflex peaks at $2 \Theta_{130 \alpha}=18.2^{\circ}$ for the $\alpha$ - and $2 \Theta_{117 \gamma}=19.4^{\circ}$ for the $\gamma$-modification as described in ${ }^{62}$ to interpret the apparent crystal modifications. More specifically as described in, ${ }^{62}$ six Lorenz curves were used for fitting the $\alpha$-modification and five to fit the amount of $\gamma$-modification.

\section{Scanning Force Microscopy}

To investigate the morphology of polypropylene samples the surface of dip-coated films were imaged using a D3100 Scanning Force Microscope equipped with a Nanoscope IIIa controller (Veeco Instruments, Santa Barbara, CA). The microscope was operated in Tapping Mode (TM) using standard micro-fabricated silicon cantilever with aluminum reflex coating (OMCL 160TS, Olympus Corporation, Japan). The cantilevers have nominal spring constants of $40 \mathrm{~N} / \mathrm{m}$; typical resonance frequencies ranged between 275 and $315 \mathrm{kHz}$.

In $\mathrm{TM}^{63}$ the topography is measured as the constant distance of the tip normal to the surface by keeping the amplitude of the oscillating tip constant. The amplitude damping $r_{\mathrm{SP}}$ conditions the applied force. $r_{\mathrm{SP}}$ is defined as the ratio of the engaged 
amplitude $\mathrm{A}$ to the free air amplitude $\left(\mathrm{A}_{0}\right)$ of the oscillating tip. Height data are complemented with simultaneously measured phase shift data. ${ }^{64}$ The phase imaging is based on energy dissipation during tapping. ${ }^{65-67}$ If an area of different viscoelasticity or adhesion is scanned, the time response of the oscillating tip changes as the tip sticks to the surface. The relative difference in the phase shift between the free oscillation in air and the oscillation while the tip is in contact with the surface is detected. Thus, the phase image outlines domains of varying material contrast at or near to the surface. For a discussion of image contrast and its dependence on scanning conditions, see. ${ }^{68}$ Amplitude and set point ratio were chosen such that the cantilever-tip assembly did not get trapped on the sample surface and that the imaging conditions warranted stiffness-dominated contrast in the phase images. Typically, in phase images recorded under these conditions harder domains show higher phase shifts, thus appearing brighter than softer areas.

In our studies the free amplitude $\mathrm{A}_{0}$ has been set to $2 \mathrm{~V}$, which is equivalent to $90 \mathrm{~nm}$, and the set point amplitude A ranges between 1.325 and $1.35 \mathrm{~V}$ resulting in an amplitude damping $r_{\mathrm{sp}}$ of about $0.65-0.7$. The phase images shown here were subjected to a first-order plane-fitting procedure to compensate for sample tilt. The magnitude of the phase signal is affected by various scan parameters, such as the precise amplitude of the free vibrating cantilever and the set point ratio. Since these values are given by the SFM software and cannot be absolutely controlled, the recorded values can only be considered as relative ones. ${ }^{64}$ Thus, phase images are presented without an absolute color scale.

\section{Heating Experiments}

To carry out the melting and crystallization experiments a commercial hot stage equipped with a Lake shore330 temperature controller (Molecular Imaging, Tempe, Arizona, USA) was added to the SFM. Dip coated samples were attached to a copper support with a thickness of $1 \mathrm{~mm}$. To ensure optimum heat transfer the silicon substrates are glued with thermo conducting epoxy glue. This support was clamped on the hot stage. The surface temperature of the sample was detected gluing a small thermocouple (IRCO-001 thermocouple J-type, diameter 0.001 in., Omega, Stamford, USA) connected to a Fluke $51 \mathrm{~K} / \mathrm{J}$ thermometer, (John Fluke Inc., Everett, USA) on a silicon wafer. Since additional heat transfer through the thin samples can be neglected, the experimental temperatures obtained from this set-up were assumed to be the surface temperatures of the sample.

SFM experiments were carried out in a homebuilt wooden box to avoid airflow. Since no contamination of the SFM cantilever due to condensation of water or other contaminants were observed, the experiments were carried out in air at $278 \mathrm{~K}$ and $30 \%$ humidity.

\section{Analysis}

The lamellar thickness was determined by a series of line sections (not shown). Any quantitative determination of the
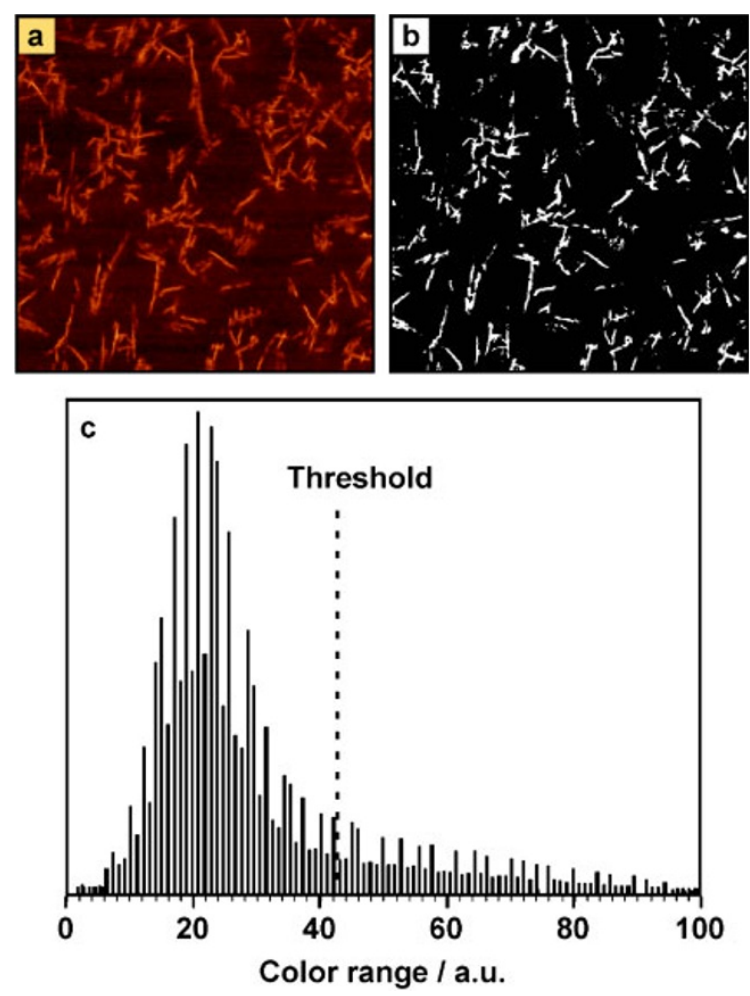

Figure 1. To determine the amount of hard phase the phase shift image (a) was converted into black-and-white picture (b). The threshold for conversion was estimated by means of the histogram (c) of the phase image (a).

lamellar dimensions as well of the total amount of crystalline phase from TM-SFM images leads to a considerable overestimate. Based on imaging of a calibration standard (Silicon gratin GT01, Silicon MDT, Moscow, Russia), the radii of the tips used in our studies were estimated to be $5-15 \mathrm{~nm}$.

To estimate the amount of crystalline phase the phase shift images (Figure 1a) are converted into binary images (Figure 1b). For this purpose the contrast of the images is leveled and the histograms are plotted. For all images, the threshold values for the conversion were adjusted at the same value, typically between 40 and 44 a.u. (Figure 1c). The amount of black and white pixels was estimated using the area analysis macro of the freeware programm ImageJ (National Institute of Health, USA). The amount of crystalline phase was determined with an accuracy of $\pm 2 \%$.

\section{Tensile Testing}

To test the mechanical properties of the melt pressed samples stretching experiments have been performed on a commercial stretching device (Zwick 1445, Zwick GmbH \& Co, Ulm, Germany). From the melt pressed film, samples with a thickness of $1 \mathrm{~mm}$ were punched using a dog-bone puncher with nominal dimensions of $20 \mathrm{~mm}$ in length and $5 \mathrm{~mm}$ in width. Areas on the films showing inhomogeneities were excluded for the tests. To calculate the nominal stress the cross sectional area has to be determined. Therefore, additional to the width the exact thickness of the samples was determined using 

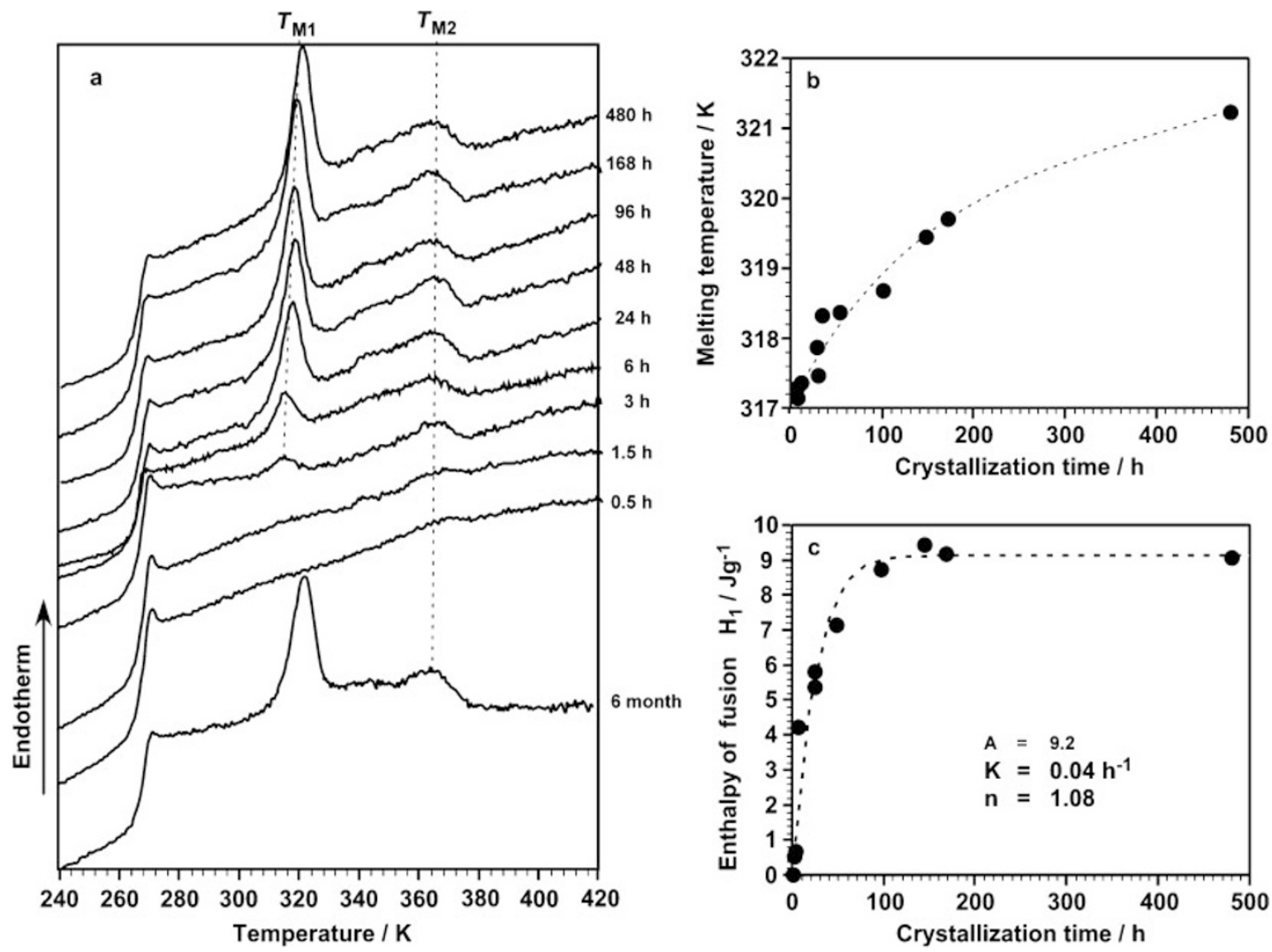

Figure 2. DSC curves taken at increasing time of crystallization (a) show a time dependent increase mainly in the first melting transition $T_{\mathrm{M} 1}$ (b) and corresponding enthalpy of fusion $\Delta H_{1}$ (c).

a micrometer screw. The initial length of the sample and their elongation were measured by the optical detection system (accuracy of the method: $\pm 0.5 \mathrm{~mm}$ ) of the used stretching device. For this purpose two optical markers were applied in the middle of the sample with a distance of $10 \mathrm{~mm}$.

To determine the stress-strain behavior of a fully crystallized sample five one year old samples were submitted to tensile testing with a stretching rate of $4 \mathrm{~mm} / \mathrm{min}$ until the sample fails. The average elongation to failure was $\lambda=$ $10.6 \pm 0.5$ with failure strength of about $4.6 \pm 0.5 \mathrm{MPa}$. To investigate the time dependent changes in the mechanical properties a melt pressed film was prepared and measured after increasing crystallization times ( $1 \mathrm{~h}$ to 6 months). To determine the reversible deformation of the samples cyclic deformation experiments were performed. Subsequently, the samples were removed from the stretching device and stored without strain for $24 \mathrm{~h}$ to allow them to recover before measuring the final sample length. The elasticity of a sample was defined as the amount of reversible deformation $\left(\varepsilon_{\text {rev }}\right)$ after elongation to a given strain rate $\varepsilon_{\text {cyc }}$ calculated by

$$
\varepsilon_{r e v}=\left(\frac{\lambda_{c y c}-\lambda_{r e l}}{\lambda_{c y c}-1}\right) \cdot 100
$$

where $\lambda_{\text {cyc }}=1_{\text {cyc }}-1_{0} / 1_{0}, \quad \lambda_{\text {rel }}=1_{\text {rel }}-1_{0} / 1_{0}$, and $1_{0}=$ initial length of the sample, $1_{\mathrm{cyc}}=$ maximum length of the sample during cyclic deformation, $1_{\text {rel }}=$ length of relaxed sample after stretching to $\lambda_{\mathrm{cyc}}$.
Further mechanical parameters, Young's modulus $E$, maximum stress $\sigma_{\max }$, plateau stress $\sigma_{\text {plat }}$ were evaluated. Young's modulus is given as the slope of the linear region (hook region) from the stress strain curve. Plateau and maximum stress is given as the stress values $\lambda=2.5$ and $\lambda=8$, respectively.

\section{RESULTS AND DISCUSSION}

\section{Crystallization Behavior}

DSC experiments performed on a melt pressed film in thermal equilibrium (Figure 2a, 6 months) show two melting transitions $M_{1}$ and $M_{2}$ indicating two fractions of crystalline aggregates, which have a total heat of fusion $\Delta H_{\text {tot }}$ of about $10 \mathrm{~J} / \mathrm{g}$. This bimodal distribution of crystals refers to a homogeneous random copolymer. ${ }^{31}$ For such copolymers it was proposed that the shorter segments will crystallize in fringed micellar structures or as ordered chain clusters $\left(\mathrm{L}_{\mathrm{M} 1}\right)$, melting at lower temperatures $T_{\mathrm{M} 1}=326.5 \mathrm{~K}$. Longer regular segments will melt at higher temperatures, $T_{\mathrm{M} 2}=368 \mathrm{~K}$. The fraction of the longer sequences $\mathrm{L}_{\mathrm{M} 2}$ creates crystals with a thickness $l$ similar to that in a homopolymer. ${ }^{32,46}$

\section{DSC}

Calorimetric measurements, where the intervals between sample preparation and measurement increased from 0.5 to $480 \mathrm{~h}$ (Figure $2 \mathrm{a}, 0.5$ to $480 \mathrm{~h}$ ) reveal a strong increase in crystallinity within the first $50 \mathrm{~h}$. After $100 \mathrm{~h}$ of crystallization 
$\Delta H_{1}$ is nearly constant. Thus, corresponding to the first peak no further crystallization occurs. Additionally, these experiments confirm the bimodal distribution of crystalline aggregates and allow following the growth of the different lamellar populations. Later could be proposed by taking a closer look to the change of the melting temperatures, $T_{\mathrm{M} 1}$ and $T_{\mathrm{M} 2}$, and the heat of fusions $\Delta H_{\mathrm{M} 1}$ and $\Delta H_{\mathrm{M} 1}$ corresponding to this temperatures. Showing differences in the grow rate of thinner and thicker crystalline aggregates, $\mathrm{L}_{\mathrm{M} 1}$ and $\mathrm{L}_{\mathrm{M} 2}$, resp. The peak at $T_{\mathrm{M} 2}=366 \mathrm{~K}$ appearing after $1.5 \mathrm{~h}$ of crystallization (Figure 2b) points out that, when the material crystallized form the melt, initially lamellae consisting of longer isotactic sequences are formed. With increasing time of crystallization the area underneath this melting peak, $\Delta H_{\mathrm{M} 2}$ becomes larger. This increase show that the lamellar fraction $\mathrm{L}_{\mathrm{M} 2}$ increases. Since the temperature is unchanged with the time, the thickness might stay constant. Most likely, lateral growth of existing lamellae or the nucleation of new lamellae may take place.

The peak, having its maximum at the lower temperature $T_{\mathrm{M} 1}$ corresponds to the melting of smaller crystalline aggregates attributed to the crystalline fraction $\mathrm{L}_{\mathrm{M} 1}$, which appears not before $3 \mathrm{~h}$ of crystallization. Both, the melting temperature $T_{\mathrm{M} 1}$ as well as the heat of fusion $\Delta H_{\mathrm{M} 1}$, increase with increasing time of crystallization (Figure $2 \mathrm{~b}$ and $2 \mathrm{c}$ ). Even that the slope of the curve (Figure 2b) decreases, even after $500 \mathrm{~h}$ crystallization time no boundary can be detected. The increase of $T_{\mathrm{M} 1}$ gives strong evidence that the smaller crystalline aggregates become thicker with time. When the enthalpy of fusion $\Delta H_{1}$ is plotted versus the crystallization time (Figure 2c) a boundary can be seen indicating no further increase of these crystalline fraction. Growing of the smaller crystalline aggregates in thickness without increasing of the crystallinity of the said fraction could only be explained by the attachment of existing crystals to the other lamellae. The correlation of the enthalpy of fusion $\left(H_{\mathrm{M} 1}\right.$, Figure $\left.2 \mathrm{c}\right)$ to the crystallization time is given by eq 2 .

$$
\mathrm{a}=\mathrm{AS} \exp ^{[-(\mathrm{Kt}) \mathrm{n}]}
$$

Except the factor A, this equation agrees with the Avramiequation, which describes the crystallization kinetics of polymers and allows the correlation of the crystallization kinetics with the type of crystalline aggregates growing. ${ }^{69}$ In this case, $\mathrm{K}$ comes out to be low $\left(0.04 \mathrm{~h}^{-1}\right)$ indicating the slow formation or growth of crystallites. Owing to the microstructure of the polypropylene material, enrichment of defects and nonisotactic sequences close to the interface between lamellae and amorphous regions seems to be plausible to explain this low crystallization rate. In case of our sample $n$ is equal to 1.08. This refers to needle like crystals growing in length.

Thus, it might be concluded that during the crystallization of low isotactic polypropylenes with statistically distributed stereoerrors first thicker lamellae $\mathrm{L}_{\mathrm{M} 2}$ were formed, which act as nuclei for thinner needle-like lamellae $\mathrm{L}_{\mathrm{M} 1}$. Similar behavior were reported in the literature ${ }^{70,71}$ and interpreted to the co-crystallization of $\alpha$ - and $\gamma$-form lamellae. In this case initially longer isotactic chains crystallize in $\alpha$-form lamellae, which act as nuclei for the epitaxial growth of $\gamma$-form crystals. $^{70}$ To proof this hypotheses, WAXS investigations during crystallization were performed.

\section{WAXS}

Wide angle X-ray scattering diagrams were used to study the crystallinity and apparent crystalline structures of the samples. Figure 3 shows the WAXS curves obtained for the sample crystallized from the melt in thermal equilibrium (Figure 3a, 6 months) and after different times of crystallization (Figure 3a, 2-240h). Similar to the DSC experiments, with increasing time of crystallization the conversion from a mainly amorphous material to a semicrystalline can be tracked. To quantify the crystallization kinetics the total crystallinity $\mathrm{X}_{\mathrm{WAXS}}$ is plotted versus the time of crystallization (Figure $3 \mathrm{~b}$ ). The plot revealed the maximum value of $18 \%$ crystallinity was reached not until $20 \mathrm{~d}$ of crystallization. This confirms the proposed slow formation of crystalline aggregates. The obtained curve does not fit the Avrami equation. This might be due to the formation of different types of crystalline aggregates as mentioned in the DSC section.

To get further information about the different crystalline phases WAXS diagrams were preformed, where the amorphous halo was subtracted from the individual curves (Figure 3c). The reflex peak at $2 \Theta_{130 \alpha}=18.2^{\circ}$ characteristic for the $\alpha$ modification appears after $2 \mathrm{~h}$ of crystallization (Figure $3 \mathrm{c}, 2 \mathrm{~h}$ ) and increase with on-going time of crystallization. This gives strong evidence that during the isothermal crystallization from the melt crystals of $\alpha$-form developed just at the beginning of the crystallization process and their amount increase with longer times of crystallization. DSC experiments reveal a peak at higher temperature $T_{\mathrm{M} 2}$ after short crystallization times (Figure 2a, 1.5 h), which was assigned to the melting of thicker lamellae. Thus, it might be concluded that while crystallization from the melt at first the longer isotactic sequences crystallize developing $\alpha$-form lamellae. This observation is in agreement with results obtained for highly isotactic polypropylenes. ${ }^{75}$ The formation of lamellae crystallized in the $\gamma$-form can be observed at longer crystallization times. The reflex peak characteristic for the $\gamma$-modification $\left(2 \Theta_{117 \gamma}=19.4^{\circ}\right)$ appears clearly at the record taken after 6 month of crystallization time (Figure 3c, 6 months). Since the melting peak at low temperatures $T_{\mathrm{M} 1}$ obtained in the DSC experiments (Figure $2 \mathrm{a}, 3 \mathrm{~h}$ ) appears at longer crystallization times of several hours, it might be reasoned that the thinner lamellae $\mathrm{L}_{\mathrm{M} 1}$ formed at longer crystallization times can be attributed to the generation of $\gamma$ form lamellae. However the crystallization times corresponding to the formation of $\gamma$-crystals from DSC $(>6 \mathrm{~h})$ and WAXS $(>240 \mathrm{~h})$ are not in absolutely agreement. This could be partly explained by the difference of the method sensitivity on overall crystallinity (DSC: $\sim 2 \%$; WAXS: $\sim 5 \%$ ) and on different crystal modification especially in WAXS diagrams where $\alpha$ - and $\gamma$-reflexes are mostly overlapping. According to the literature the mentioned results might be explained by formation of $\gamma$ - and mixed $\alpha / \gamma$-form crystals nucleated over the initially preformed $\alpha$-form crystals. ${ }^{70,75}$ Therefore it might 

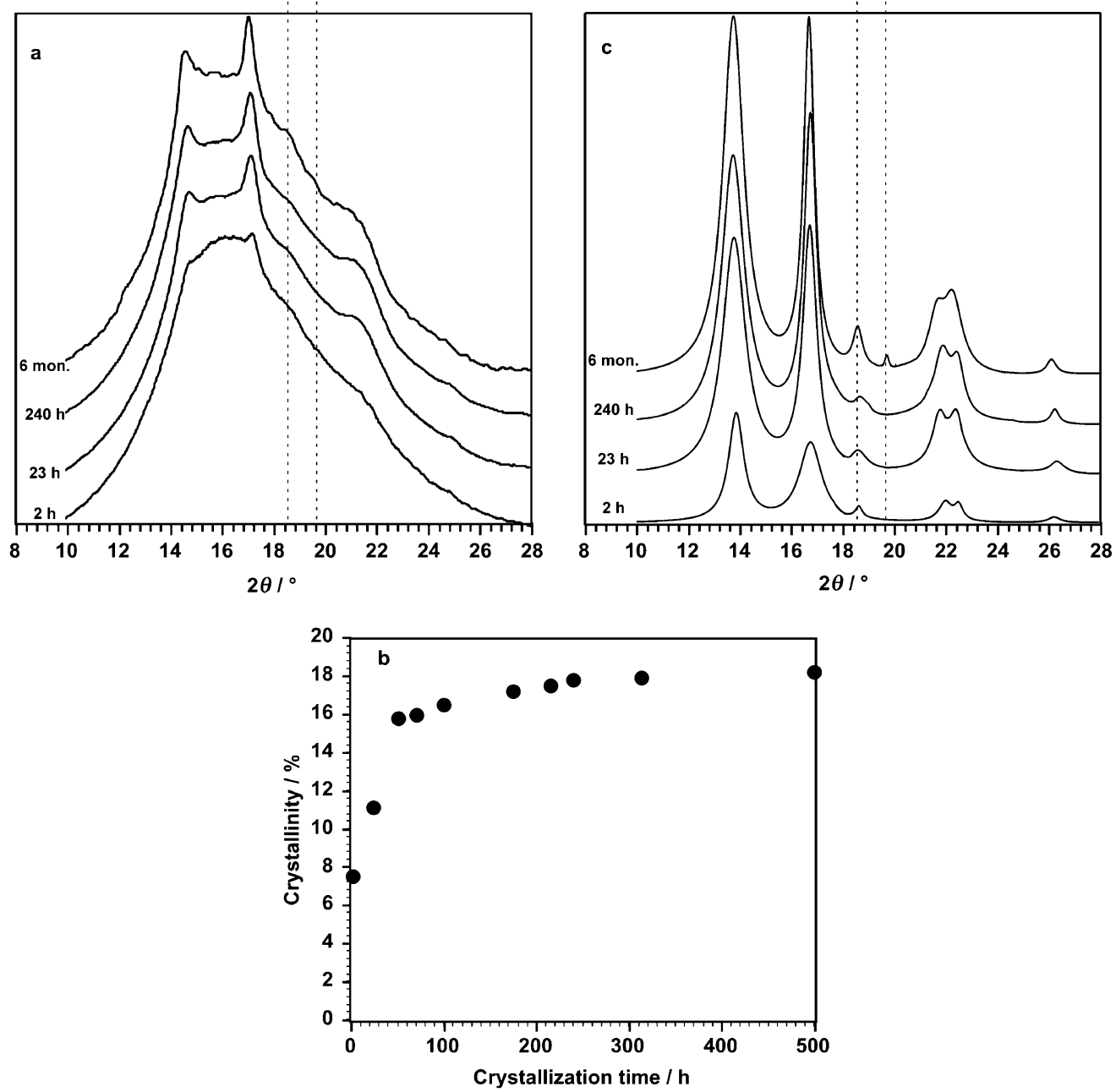

Figure 3. WAXS curves taken at increasing time of crystallization reveal increasing amount of crystallites with time (a). Time dependent increase in crystallization confirms the slow formation and growth of crystalline aggregates (b). Subtracting the amorphous halo gives further insight in the crystallization kinetics of $\alpha$ - and $\gamma$-form crystallites.

be reasonable that the thin lamellae formed at longer crystallization times are rather arranged in a $\alpha / \gamma$-modification than in pure $\gamma$-modification. Later interpretation will be supported by the increase in the lamellar fraction $\mathrm{L}_{\mathrm{M} 1}$ and the increase in $\alpha$-form crystalline aggregates refer to the additional formation of thinner $\alpha$-phase lamellae. This confirms the assumption that the primary crystallized $\alpha$-phase lamellae act as nuclei for the secondary crystallization of $\alpha$-, $\gamma$-form lamellae and mixtures there from.

\section{Scanning Force Microscopy}

The fact that different fractions of $\alpha$ - and $\gamma$-modification observed after different times of crystallization suggests that the samples reveal morphology where both lamellar types occur. Therefore the polymer structure was investigated using TM-SFM. For the SFM hot stage experiments thin films on a silicon substrate were used, which are known to reflect the volume structure of semicrystalline materials. The dip coated (Figure 4a) reveal crystallites developed as individual or bundled rodlike structures. The rod-like crystals appear with an average thickness of $10 \pm 3 \mathrm{~nm}$ (Owing to tip convolution any quantitative determination of the thickness of these crystalline lamellae from TM-SFM leads to a considerable overestimate. Based on calibration standards the tip radius of the used tip ranges from $5-15 \mathrm{~nm}$.) determined from crosssectional plots. An amount of hard phase of about $25 \pm 5 \%$ has been found. Assuming that only isotactic sequences form these crystals, isotactic blocks with an average length of about 40 monomers will form the crystalline aggregates. Additionally, crosshatched structures appear where the angle between the crosshatched lamellae is about $80 \pm 5^{\circ}$ (Figure 4a). On the basis of a great many of literature given for i-PP, ${ }^{70}$ such a structure were assigned to lamellae crystallized $\alpha$-modification. The lamellae seemed to be embedded in a thin slightly darker layer. According to the color-coding this layer is harder than the surrounding matrix, but softer than lamellae. Most probably this layer consist of shorter isotactic, which are parallel aligned, but not transformed to the crystalline state. These results show, that the morphology of dip coated films reflects the structure of thin solvent crystallized films in a good way. Therefore, the dip 

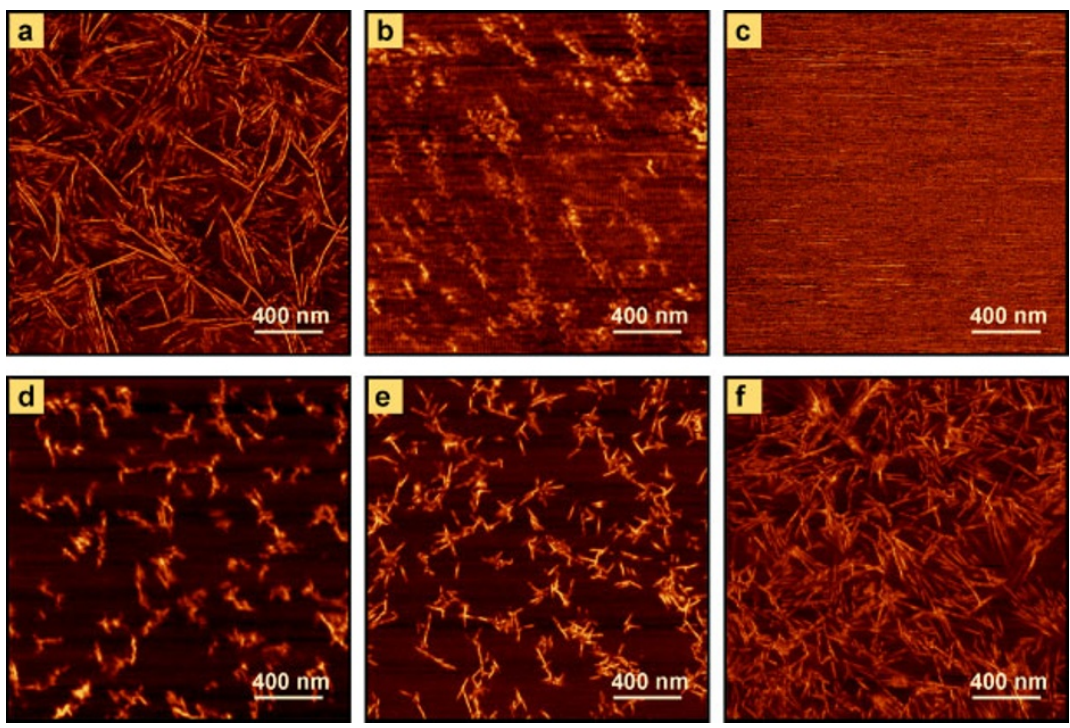

Figure 4. Phase images of dip coated films recorded at different temperatures. At room temperature $295 \mathrm{~K}$ (a), at $350 \mathrm{~K}$ (b), at $375 \mathrm{~K}$ (c), and cooled down to $340 \mathrm{~K}(\mathrm{~d}), 295 \mathrm{~K}(\mathrm{e})$ and after $6 \mathrm{~h}$ at room temperature $295 \mathrm{~K}(\mathrm{f})$

coated films can be used as a model system for the crystallization studies.

To follow the complete melting and recrystallization of a low isotactic polypropylene film phase shift images were taken in situ under isothermal conditions by TM-SFM in a temperature range between 300 and $380 \mathrm{~K}$ (Figure 4a-4f). The TMSFM phase images provide excellent contrast between the soft featureless amorphous region and the crystallites embedded in the melt like region at all temperatures similar as stereoblock polypropylenes. ${ }^{64,68}$ Heating a dip coated film from room temperature (Figure 4a) up to $375 \mathrm{~K}$ (Figure 4c) allows one tracking the partially melting of crystalline lamellae. At $350 \mathrm{~K}$ (Figure $4 \mathrm{~b}$ ), the number of rodlike structures is reduced to mainly longer, namely thicker rods before. Thinner lamellae formed by shorter isotactic blocks $\mathrm{L}_{\mathrm{M} 1}$ and correlated to the melting transition $\mathrm{M}_{1}$ have vanished. A closer look to the remaining lamellae reveals that they are no longer homogeneous rods, but small crystalline blocks separated by amorphous domains are aligned in a row like pearls on a chain. Thus, most likely the present lamellae are not homogeneous but composed of aligned crystalline blocks. The block-like aggregates are stable until the temperature gets above $370 \mathrm{~K}$. Thus, according to DSC experiments, these blocky features might be attributed to the lamellar fraction $\mathrm{L}_{\mathrm{M} 2}$, melting at higher temperatures. To get a homogeneous melt (Figure 4c), the sample has to be heated for at least one hour at $375 \mathrm{~K}$, which is above the second melting temperature $T_{\mathrm{M} 2}$ found in DSC.

To follow the nucleation and growth of lamellar crystals, the sample was cooled down from the melted state (Figure 4c) to room temperature (Figure 4d-4f). Next scan was performed when temperature of $340 \mathrm{~K}$ was reached, which is below $T_{\mathrm{M} 2}$. At this temperature stiff features appeared in the homogeneous melt, which indicates the nucleation crystalline aggregates. These first lamellae remained unchanged for considerable time. At this early stage of crystallization mainly individual or bundled rods with lengths ranging from $20-100 \mathrm{~nm}$ can be seen, which are reported to be lamellar nuclei of polypropylene lamellae. ${ }^{61,76-78}$ The limited resolution in the experiment mentioned above makes the unequivocal differentiation of small initially growing crystallites impossible and the fine structure of the lamellae cannot be depicted. This behavior is likely related to the lack of crystallizable material in the region near to the growth front. Even though the crystals are clearly observed by SFM phase images, the overall crystallinity was found to be low. Within the $2 \times 2 \mu \mathrm{m}^{2}$ range an amount of $8 \pm 3 \%$ of hard phase was determined referring to a sample crystallinity in the same range (Figure 4d).

Cooling the sample down to room temperature (Figure 4e), the contrast between the amorphous and the hard phase improves. Thus, the lamellae appear more clearly. At the same time, a slight increase of the hard phase to $10 \pm 3 \%$ was found. The higher amount of hard phase is most probably caused by the further lateral growth of the rod, until they reach a length up to $200 \mathrm{~nm}$. At this early stage of crystallization also small amounts of branched lamellae were formed, which extend up to $50 \mathrm{~nm}$ in the amorphous phase. The observed elongated features can be assigned to edge-on oriented lamellae, similar to the ones observed for stereoblock low isotactic polypropylenes. ${ }^{16,60,76-78}$ Branching angles of $80 \pm 5^{\circ}$ and $40 \pm 5^{\circ}$ can be detected, giving strong evidence that lamellae were formed consisting of $\alpha$ - as well as $\gamma$-modification.

Since the relative growth rates have shown to be small, the crystallization process can be followed in detail with relative high temporal resolution. To study the crystallization kinetics, SFM phase images were performed. In Figure 5 different stages of lamellar development at room temperature were depicted. These images are snapshots of a consecutively captured series of typical 10 to 15 phase images started immediately after reaching $295 \mathrm{~K}$ (Figure 5a) up to $280 \mathrm{~min}$ of crystallization (Figure 5f). 

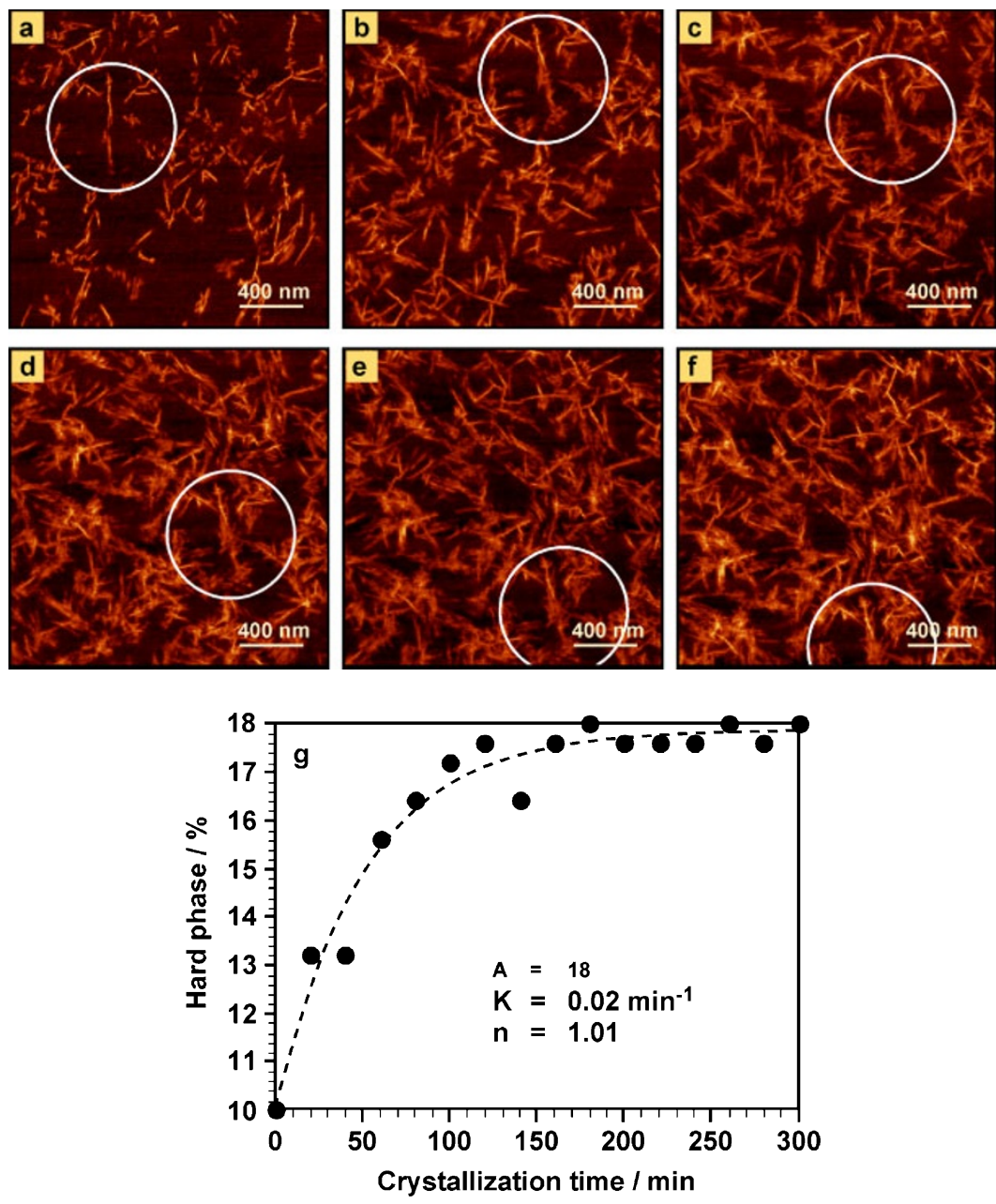

Figure 5. Recrystallization at room temperature after heating up to $350 \mathrm{~K}$ show increasing amount of hard phase immediately after cooling; 0 min (a) and at increasing periods of time: $60 \mathrm{~min}(\mathrm{~b}), 120 \mathrm{~min}(\mathrm{c}), 180 \mathrm{~min}(\mathrm{~d}), 240 \mathrm{~min}(\mathrm{e})$ and $280 \mathrm{~min}(\mathrm{f})$. Amount of hard phase as function of the crystallization time (g).

After reaching room temperature (Figure 5a), crystalline lamellae with lengths between 50 and $400 \mathrm{~nm}$ appeared. For these lamellae a typical thickness of $10 \pm 3 \mathrm{~nm}$ was estimated. Thus, stereoregular segments with $40 \pm 8$ monomers in consecutive isotactic sequence will contribute to this lamellar fraction $\left(\mathrm{L}_{\mathrm{M} 2}\right)$. The development of one crystalline aggregate showing up as longer rodlike lamellae is observed in detail. Therefore a circle marks the region around this feature. The most eye-catching fact is that this initially formed lamellar aggregate does not grow further in length, but acts as stable nuclei for the edge-on growth of secondary lamellae, which shows lengths up to $50 \mathrm{~nm}$ (Figure 5b). The preferred branching angle between the primary lamellae and the secondary ones is $40 \pm 4^{\circ}$. This confirms the suggested edge-on crystallization of $\gamma$-form lamellae. The observation that the $\gamma$-form nucleated on preformed $\alpha$-form crystals is consistent with results reported by Lotz et al..$^{79}$ and Thomann et al. ${ }^{80-82}$ At a later stage of crystallization (Figure 5e) secondary lamellae are formed at all primary lamellae. Many of them reveals branching angles of $40 \pm 3^{\circ}$, but also some lamellae grow with a branching angle of $80 \pm 5^{\circ}$ referring to the additional formation of $\alpha$-phase lamellae. Rated by the SFM images, the secondary lamellae are thinner than the primary lamellae. This observation corroborates the findings from DSC experiments that shorter isotactic blocks will form this lamellar fraction by secondary crystallization, observed as crystallization having lower crystal growth rate. The lamellae steadily grow until the interspace is filled, and a total amount of $18 \pm 3 \%$ of hard phase is reached.

Determining the amount of hard phase for this series of phase shift images and plotting the values versus the time results in the curve shown in Figure $5 \mathrm{~g}$. The curve can fitted using eq 2. An Avrami exponent of 1 can be estimated which is in accordance to the macroscopic value observed for the growth of the lamellar fraction $\mathrm{L}_{\mathrm{M} 1}$ in DSC experiments. This confirms the assumption that the thinner lamellae observed in SFM phase shift images can be correlated to the thinner lamellar fraction $\mathrm{L}_{\mathrm{M} 1}$ detected with DSC. The SFM phase images approves that this crystalline fraction consists of needle-like structures growing in length.

\section{Mechanical Testing}

To study the time dependent changes in mechanical proper- 

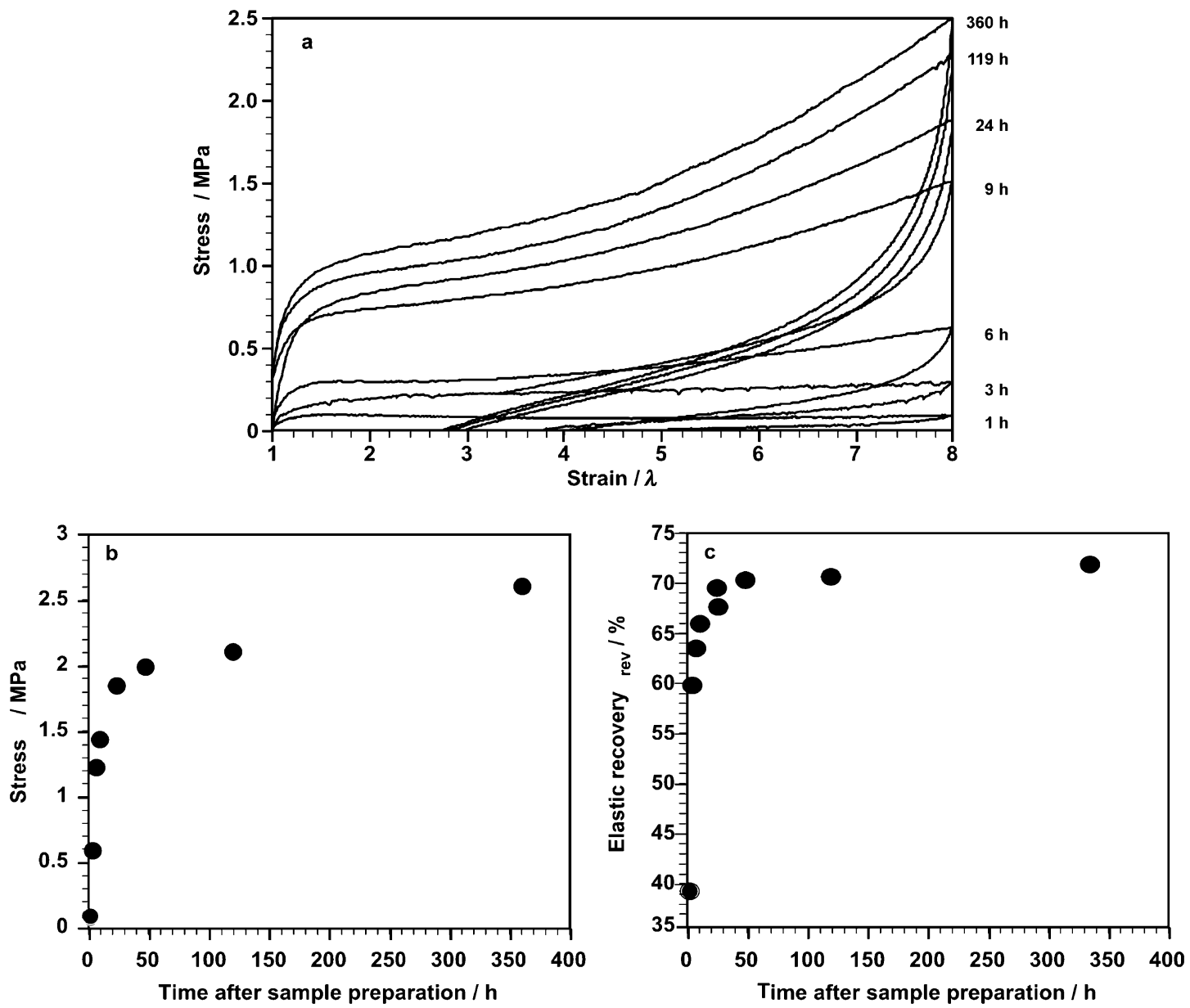

Figure 6. Cyclic stress strain curves performed after different recrystallization times reveal increasing in elastic recovery (a), increase in maximum stress $\sigma_{\text {max }}$ at $\lambda=8$ at increasing crystallization time (b) and elastic recovery $\varepsilon_{\mathrm{rev}}$ (c) refers to an increasing amount of crosslinks.

ties cyclic strain experiments were preformed after different crystallization times. Mechanical cycles of stretching and relaxation have been performed at room temperature on heat treated, solvent crystallized films and the corresponding stressstrain curves have been recorded (Figure 6). The finite values observed for both, the maximum stress $\sigma_{\max }$ and the reversible elongation $\lambda_{\text {rev }}$, observed in the first experiment (Figure 6,1 h) indicates that after $1 \mathrm{~h}$ crystallization time the amount of crystalline crosslinks generated is sufficient to prevent the sample from viscous flowing. These results are in agreements with the findings from DSC, WAXS and SFM, all showing that a small amount of crystalline domains were generated relatively quick.

The stress-strain curves taken at increasing time of crystallization (Figure 6a) illustrate clearly an improvement of mechanical parameters with increasing crystallization time. This gives strong evidence of the formation of a larger quantity of crosslinks during the examination period. Owing to the higher crosslinking density the material is reinforced. The reinforcement can be detected as increasing mechanical stress $\sigma_{\max }$. Additionally, the enhanced elastic properties unveil as an increase in the elastic recovery $\lambda_{\text {rev }}$ or the reversible deformation $\varepsilon_{\text {rev }}$, respectively. To illustrate the time dependent mechanical parameters, maximum stress $\sigma_{\max }$ and reversible deformation $\varepsilon_{\text {rev }}$ are plotted versus the time (Figure $6 \mathrm{~b}$ and $6 \mathrm{c}$ ). The maximum stress $\sigma_{\max }$ increased from $0.1 \mathrm{MPa}$ at one hour crystallization time to $2.4 \mathrm{MPa}$ at $15 \mathrm{~d}$ after sample preparation (Figure 6b) and stays more or less constant for longer crystallization times. Similarly, the reversible deformation $\varepsilon_{\text {rev }}$ increases from $38 \%$ at short times of crystallization to $75 \%$ at long time crystallization (Figure 6c) within less than $100 \mathrm{~h}$. The main rising in maximum stress $\sigma_{\max }$ and reversible deformation $\varepsilon_{\text {rev }}$ can be found within the first $50 \mathrm{~h}$ of crystallization, which corresponds very well to the increase in crystallinity observed in DSC and WAXS experiments. The correlation of the increasing reinforcement with an increasing amount of crystalline aggregates demonstrates that these features generate a network responsible for the elastic behavior of the material.

Compared to other low isotactic polypropylenes ${ }^{14,42,83-85}$ an elastic recovery of $\lambda_{\text {rev }}>70 \%$ found for the investigated polypropylenes with statistically distributed steroerrors is high. Most likely, the great number of small crystalline blocks randomly distributed within the amorphous provides a more perfect crystalline network as the stereoblock polypropylenes. Nevertheless, this elastic recovery is below the one obtained 
for chemically crosslinked rubbers. Most likely this discrepancy can be attributed to the irreversible change in the crystalline structure during deformation. It is therefore of importance to study the deformation induced changes in morphology on the microscopic level.

\section{CONCLUSION}

The aim of this paper was to analyze whether the distribution of the hard, crystalline segments influences the properties of propene based TEP's. To achieve this goal, the morphology, the crystallization behavior and the mechanical properties of a low isotactic polypropylene with statistically incorporated stereoerrors were investigated. To figure out how and to what extent this polymer crystallizes, time and temperature dependent crystallization experiments of a sample containing $36 \%$ isotactic sequence are performed using DSC, WAXS and SFM.

In the DSC curve of this polymer two distinct melting transitions appear evidenced a polymer with a bimodal distribution of isotactic sequences. The melting peaks can be attributed to two crystalline fractions consisting of chains with different block length. The crystalline fraction $\mathrm{L}_{\mathrm{M} 2}$ melting at higher temperature contains longer isotactic sequences with $\mathrm{n}_{\mathrm{iso}, 2}=30 \pm 0.5$ monomers calculated. The other crystalline fraction $\mathrm{L}_{\mathrm{M} 1}$ consisting mainly of shorter isotactic blocks with a calculated length of $n_{\text {iso, } 1}=22 \pm 0.5$ melting at lower temperature. SFM phase shift imaging revealed the phaseseparated structure of the polymers where imperfect lamellae are randomly distributed within an amorphous matrix. The lamellae are composed of bundled chains crystallized in a granular morphology. Different preferred branching angles $\left(40^{\circ}\right.$ and $\left.80^{\circ}\right)$ between adjacent lamellae confirm the formation of both $\alpha$ - and $\gamma$-form crystallites. This shows that the investigated low isotactic polypropylenes resemble lamellar structures known for highly isotactic polypropylenes, ${ }^{72}$ but the shorter regular blocks lead to mainly imperfect lamellae. Hence, similar to low isotactic stereoblock polypropylenes, also low isotactic polypropylene with randomly distributed stereoerrors form structures remiscent of highly isotactic PP. Unless as in amorphous TEP's, random and block polypropylenes cannot be discriminated owing to their morphology.

WAXS experiments on melt pressed films revealed that metallocene-made low isotactic polypropylenes containing a random distribution of defects posses a degree of crystallinity $<18 \%$ and crystallizes in mixed $\alpha / \gamma$-form aggregates. The experiments show that the formation of the mixed $\alpha / \gamma$-form is a result of two competing kinetic and thermodynamic effects. ${ }^{86,87}$ During the isothermal crystallization from the melt initially crystals of the $\alpha$-form were developed consisting of longer isotactic sequences. The formation of crystals of $\gamma$-form is slow and can be observed only at longer crystallization times. It is thought that this lamellar fraction contains mainly shorter isotactic sequences. Time dependent SFM phase shift images confirm these results.

SFM experiments allow the visualization of the nucleation of $\gamma$-form lamellae over the initially formed crystals of $\alpha$-form.
Thus, also low isotactic polypropylene with randomly distributed stereoerrors forms similar structures reminiscent of highly isotactic PP. The main effect of defects is shortening the length of the regular isotactic crystallizable sequences which favor the crystallization in the $\gamma$-form.

The mechanical tests revealed that the high amount of crystalline domains formed after longer times of crystallization provides a very flexible network, which has an excellent elastic recovery. One disadvantage of this material is the slow crystallization rate mainly due to the low amount of crystallizable, regular sequences. To get the maximum elastic recovery the sample has to be stored about two weeks, which limits the industrial applications. Nevertheless, the investigations clearly show that the distribution of crystalline crosslinks can be directed by changing the polymerization conditions. This opens the possibility to tailor the mechanical properties of these elastomeric polypropylenes by changing the polymer microstructure.

Acknowledgment. One of us present has been generously supported by the Margarethe-von-Wrangell foundation. Prof. O. Marti and all the members of the department of Experimental Physics are acknowledged for their support, especially, M. Kienzle and M. Asbach for performing microtom cuts and DSC.

Received: June 2, 2008

Accepted: July 27, 2009

Published: September 10, 2009

\section{REFERENCES}

1. L. Resconi, L. Cavallo, A. Fait, and F. Piemontesi, Chem. Rev., 100, 1253 (2000).

2. J. W. Collette, C. W. Tullock, R. N. MacDonald, W. H. Buck, A. C. L. Su, J. R. Harrell, R. Mulhaupt, and B. C. Anderson, Macromolecules, 22, 3851 (1989).

3. J. W. Collette, D. W. Ovenall, W. H. Buck, and R. C. Ferguson, Macromolecules, 22, 3858 (1989).

4. S. D. Ittel, J. Macromol. Sci. Chem., A27, 9 (1990).

5. D. T. Mallin, M. D. Rausch, Y. G. Lin, S. Dong, and J. C. W. Chien, J. Am. Chem. Soc., 112, 2030 (1990).

6. A. Bravakis, L. E. Bailey, M. Pigeon, and S. Collins, Macromolecules, 31, 1000 (1998).

7. G. W. Coates and R. M. Waymouth, Science, 267, 217 (1995).

8. M. D. Bruce, G. W. Coates, E. Hauptman, R. M. Waymouth, and J. W. Ziller, J. Am. Chem. Soc., 119, 11174 (1997).

9. G. Natta, G. Mazzanti, G. Crespi, and G. Moraglio, Chim. Ind., 39, 275 (1957).

10. G. Natta, U. S. Patent (1965).

11. "Thermoplastic Elastomers," G. Holden, N. R. Legge, R. P. Quirk, and H. E. Schroeder, Ed., Hanser Gardner, 1996.

12. E. D. Carlson, M. T. Krejchi, C. D. Shah, T. Terakawa, R. M. Waymouth, and G. G. Fuller, Macromolecules, 31, 5343 (1998).

13. Y. Hu, E. D. Carlson, G. G. Fuller, and R. M. Waymouth, Macromolecules, 32, 3334 (1999).

14. R. Kravchenko, A. Masood, R. M. Waymouth, and C. L. Myers, J. Am. Chem. Soc., 120, 2039 (1998).

15. E. D. Carlson, G. G. Fuller, and R. M. Waymouth, Macromolecules, 32, 8100 (1999).

16. H. Schönherr, W. Wiyatno, J. Pople, C. W. Frank, G. G. Fuller, P. 
GA, and R. M. Waymouth, Macromolecles, 35, 2654 (2002).

17. G. J. Natta, J. Polym. Sci., 34, 531 (1959).

18. S. Bensason, J. Minick, A. Moet, S. Chum, A. Hiltner, and E. Baer, J. Polym. Sci., Part B: Polym. Phys., 34, 1301 (1996).

19. T. Ho and J. M. Martin, in "Metallocene-Based Polyolefins" J. Scheirs and W. Kaminsky, Ed., Wiley, Chichester, 2000, p 175.

20. G. Holden, in "CRC Press," J. Salamone, Ed., Boca Raton, 1996, p 8343.

21. E. M. Frick, S. Andrew, R. Zalusky, and M. A. Hillmyer, Biomacromolecules, 4, 216 (2003).

22. W. Gabrielse, M. Soliman, and K. Dijkstra, Macromolecules, 34, 1693 (2001).

23. S. Velankar and S. L. Cooper, Macromolecules, 33, 382 (2000).

24. M. Konrad, A. Knoll, G. Krausch, and R. Magerle, Macromolecules, 33, 5518 (2000).

25. N. Rehse, A. Knoll, R. Magerle, and G. Krausch, Macromolecules, 36, 3261 (2003).

26. C. De Rosa, F. Auriemma, M. Paolillo, L. Resconi, and I. Camurati, Macromolecule, 38, 9143 (2005).

27. R. G. Alamo, M.-H. Kim, M. J. Galante, J. R. Isasi, and L. Mandelkern, Macromolecules, 32, 4050 (1999).

28. J. C. Randall, R. G. Alamo, P. K. Agarwal, and C. J. Ruff, Macromolecules, 36, 1572 (2003).

29. B. Wunderlich, "Macromolecular Physics," Academic press, New York, 1973, Vol. 1-3.

30. I. C. Sanchez and R. K. Eby, Macromolecules, 25, 638 (1975).

31. A. Alizadeh, L. Richardson, J. Xu, S. McCartney, H. Marand, Y. W. Cheung, and S. Chum, Macromolecules, 32, 6221 (1999).

32. B. Crist and D. N. Williams, J. Macromol. Sci., Part B: Phys., 39, 1 (2000).

33. D. Fischer and R. Mülhaupt, Macromol. Chem. Phys., 195, 1433 (1994).

34. C. De Rosa, F. Auriemma, T. Circelli, and R. M. Waymouth, Macromolecules, 35, 3622 (2002).

35. C. Averbuj, E. Tish, and M. S. Eisen, J. Am. Chem. Soc., 120, 8640 (1998).

36. M. Xie, Q. Wu, and S. Lin, Acta Polym. Sym., 1, 15 (1999).

37. K. Kimura, K. Takaishi, T. Matsukawa, T. Yoshimura, and H. Yamazaki, Chem. Lett., 571 (1998).

38. W. J. Gauthier and S. Collins, Macromolecules, 28, 3779 (1995).

39. G. H. Llinas, S.-H. Dong, D. T. Mallin, M. D. Rausch, Y.-G. Lin, H. H. Winter, and J. C. W. Chien, Macromolecules, 25, 1242 (1992).

40. J. C. W. Chien and M. D. Rausch, U. S. Patent 5.756 .614 (1998).

41. R. M. Waymouth, G. W. Coates, and E. M. Hauptman, U. S. Patent 5.594.080 (1997).

42. S. A. Miller and J. E. Brecaw, Organometallics, 21, 934 (2002).

43. U. Dietrich, M. Hackmann, B. Rieger, M. Klinga, and M. Leskelä, J. Am. Chem. Soc., 121, 4338 (1999).

44. G. Müller and B. Rieger, Prog. Polym. Sci., 27, 815 (2002).

45. B. Rieger, C. Troll, and J. Preuschen, Macromolecules, 35, 5742 (2002).

46. X. Zhu, D. Yan, and Y. J. Fang, J. Phys. Chem. B., 105, 1246 (2001).

47. D. C. Bassett, in "Principles of Polymer Morphology," Cambridge University Press, Cambridge, 1981.

48. G. R. Strobl, in "The physics of polymers," Springer, Berlin, 1996.

49. R. Pearce and G. Vancso, Polymer, 39, 1237 (1998).

50. J. M. Schultz and M. J. Miles, J. Polym. Sci., Part B: Polym. Phys., 36, 2311 (1998)

51. J. K. Hobbs, T. J. McMaster, M. J. Miles, and P. J. Barham, Polymer, 39, 2437 (1998).

52. T. J. McMaster, J. K. Hobbs, P. J. Barham, and M. J. Miles, Probe Microsc., 1, 43 (1997).
53. L. Li, C.-M. Chan, K. L. Yeung, J.-X. Li, K.-M. Ng, and Y. Lei, Macromolecules, 34, 316 (2001).

54. Y. Kikkawa, Y. Inoue, H. Abe, T. Iwata, and Y. Doi, Polymer, 42, 2707 (2001)

55. W. Zhou, S. Z. D. Cheng, S. Puttharnarat, R. K. Eby, D. H. Reneker, B. Lotz, S. Magonov, E. T. Hsieh, R. G. Geerts, S. J. Palackal, G. R. Hawley, and M. B. Welch, Macromolecules, 33, 6861 (2000).

56. L. G. M. Beekmans and G. J. Vancso, Polymer, 41, 8975 (2000).

57. G. J. Vancso, G. Liu, J. KargerKocsis, and J. Varga, Colloid Polym. Sci., 38, 491 (1999).

58. J. K. Hobbs, A. D. L. Humphris, and M. J. Miles, Macromolecules, 34, 5508 (2001).

59. H. Schönherr and C. W. Frank, Macromolecules, 36, 1188 (2003).

60. H. Schönherr and C. W. Frank, Macromolecules, 36, 1199 (2003).

61. H. Schönherr, C. J. Waymouth, and C. W. Frank, Macromolecules, 36, 2412 (2003).

62. A. Boger, B. Heise, C. Troll, O. Marti, and B. Rieger, Eur. Polym. J., 43, 634 (2007).

63. Q. Zhong, D. Inniss, K. Kjoller, and V. Elings, Surf. Sci., 290, 688 (1993).

64. T. J. Morkved and H. M. Jaeger, Europhys. Lett., 40, 643 (1997).

65. J. P. Cleveland, B. Anczykowski, A. E. Schmid, and V. B. Elings, Appl. Phys. Lett., 72, 2613 (1998).

66. J. Tamayo and R. Garcia, Appl. Phys. Lett., 73, 2926 (1998).

67. W. W. Scott and B. Bhushan, Ultramicroscopy, 97, 151 (2003).

68. G. Bar, Y. Thomann, R. Brandsch, H.-J. Cantow, and M.-H. Whangbo, Langmuir, 13, 3807 (1997).

69. B. Wunderlich, in "Macromolecular Physics," Academic Press, New York, 1976, Vol. II.

70. S. Brückner, S. V. Meille, V. Petraccone, and B. Pirozzi, Prog. Polym. Sci., 16, 361 (1991).

71. S. V. Meille, S. Brückner, and W. Porzio, Macromolecules, 23, 4114 (1990).

72. R. G. Alamo, J. A. Blanco, P. K. Agarwal, and J. C. Randall, Macromolecules, 36, 1559 (2003).

73. C. De Rosa, F. Auriemma, A. Di Capua, L. Resconi, S. Guidotti, I. Camurati, I. E. Nifant'ev, and Laishevtsev, J. Am. Chem. Soc., 126 17040 (2004).

74. D. Fischer and R. Mülhaupt, Macromol. Chem. Phys., 195, 1433 (1994).

75. C. De Rosa, F. Auriemma, and L. Resconi, Macromolecules, 38, 10080 (2005).

76. D. C. Bassett and R. H. Olley, Polymer, 25, 935 (1984).

77. R. H. Olley and D. C. Bassett, Polymer, 30, 399 (1989).

78. B. Lotz and J. C. Wittmann, J. Polym. Sci., Part B: Polym. Phys., 24, 1541 (1986).

79. B. Lotz, S. Graff, C. Straupe, and J. C. Wittmann, Polymer, 32, 2902 (1991).

80. R. Thomann, C. Wang, J. Kressler, and R. Mülhaupt, Macromolecules, 29, 8425 (1996).

81. R. Thomann, J. Kressler, B. Pudolf, and R. Mülhaupt, Polymer, 37, 2635 (1996).

82. R. Thomann, J. Kressler, S. Setz, R. Wang, and R. Mülhaupt, Polymer, 37, 2627 (1996).

83. C. De Rosa, F. Auriemma, and C. Perretta, Macromolecules, 37, 6843 (2004).

84. A. R. Siedle, PCT 1999.

85. W. Wiyatno, J. Pople, A. P. Gast, R. M. Waymouth, and G. G. Fuller, Macromolecles, 35, 8488 (2002).

86. C. De Rosa, F. Auriemma, T. Circelli, and R. M. Waymouth, Macromolecules, 35, 3622 (2002).

87. F. Auriemma and C. De Rosa, Macromolecules, 35, 9057 (2002). 